\title{
Activity-Dependent Differential Transmitter Release in Mouse Adrenal Chromaffin Cells
}

\author{
Tiberiu Fulop, Stephen Radabaugh, and Corey Smith \\ Department of Physiology and Biophysics, Case Western Reserve University, Cleveland, Ohio 44106-4970
}

\begin{abstract}
Chromaffin cells of the adrenal medulla are a primary neuroendocrine output of the sympathetic nervous system. When stimulated, they secrete a host of transmitter molecules, including catecholamines and neuropeptides, through the fusion of dense core secretory granules with the cell surface. At basal firing rates, set by the sympathetic tone, chromaffin cells selectively release catecholamines at a modest rate. Stress-mediated sympathetic activation leads to elevated catecholamine secretion and also evokes neuropeptide release. Catecholamines and neuropeptides are copackaged in the same granules; thus, it is unclear how this activity-dependent differential transmitter release is achieved. In this report, we use electrophysiological, electrochemical, fluorescence, and immunocytochemical approaches to quantify transmitter release under physiological electrical stimulation at the single cell level. We provide data to show that chromaffin cells selectively release catecholamine under basal firing conditions but release both neuropeptides and catecholamines under conditions that match acute stress. We further show that this differential transmitter release is achieved through a regulated activity-dependent dilation of the granule fusion pore. Thus, chromaffin cells may regulate release of different transmitters through a simple size-exclusion mechanism.
\end{abstract}

Key words: chromaffin; catecholamine; neuropeptide; exocytosis; endocytosis; trafficking; stress

\section{Introduction}

Chromaffin cells of the adrenal medulla respond to sympathetic excitation by releasing transmitter molecules into the circulation (Kidokoro and Ritchie, 1979). Under basal conditions, chromaffin cells fire action potentials and release catecholamine at a basal rate set by the sympathetic tone and contribute to the regulation of the "breed and feed" state of energy storage. In this state, secreted catecholamines regulate homeostatic functions including vascular tone, enteric activity, and insulin release. Acute stress causes sympathetic activation and increases catecholamine release manyfold, setting the organism into a "fight or flight" state of energy expenditure. This results in increased cardiac output, shunted blood flow from the viscera to skeletal muscles, and increased glucagon secretion. In addition, stress activation causes chromaffin cells to release neuropeptides including the chromogranins, neuropeptide Y (NPY), and enkephalin that all play a role in the peripheral sympathetic response. Chromogranins represent the majority of peptide cargo in chromaffin granules (O'Connor and Frigon, 1984) and are cleaved after exocytosis to the neuroactive catestatins. In the periphery, NPY acts to modulate vasoconstriction. Enkephalin is an endogenous opioid that acts as an analgesic and allows an organism to focus on escape or defense rather than tending to injury or fatigue. Together these

Received May 20, 2005; revised July 4, 2005; accepted July 5, 2005.

This work was supported by National Science Foundation Grant IBN-0344768 and National Institutes of Health Grants 1R01NS052123 (C.S.), T32HL007887 (S.R.), and T32HL07653 (T.F.). We thank Drs. Luis Polo-Parada, Shyue-An Chan, and Stephen Vogel for helpful advice on experimental design and comments on this manuscript.

Correspondence should be addressed to Corey Smith, Department of Physiology and Biophysics, Case Western Reserve University, Cleveland, OH 44106-4970. E-mail: corey.smith@case.edu.

D01:10.1523/JNEUROSCI.2042-05.2005

Copyright $\odot 2005$ Society for Neuroscience $\quad$ 0270-6474/05/257324-09\$15.00/0 neuropeptides exist within a gel-like matrix in the secretory granules (Rahamimoff and Fernandez, 1997).

Although much attention has been paid to the release of catecholamine from chromaffin cells, peptide transmitter release remains less studied. Release of neither transmitter class has been extensively studied under physiological electrical stimulation at the cellular level. Catecholamines and neuropeptides are copackaged in the same granule (Winkler and Westhead, 1980); thus, it was assumed that both types of transmitter are released by a single exocytic mechanism (Viveros et al., 1969). However, this is inconsistent with reports of activity-dependent differential release of catecholamine and neuropeptides from chromaffin cells (Takiyyuddin et al., 1990, 1994; Watkinson et al., 1990; Cavadas et al., 2002), clonal PC-12 cells (Wilson et al., 1981), and transmitter levels measured in the circulation (Giampaolo et al., 2002). Thus, the idea that granule fusion represents the final step in the control of transmitter release from chromaffin granules is insufficient to describe the observed behavior.

Here, we use electrophysiological, fluorescence imaging, immunocytochemical, and electrochemical amperometric techniques to show activity-dependent differences in the mode of granule fusion under physiological stimulation. We conclude that basal firing preferentially evokes catecholamine release through a restricted granule fusion intermediate (an $\Omega$ figure), resembling a "kiss and run" mechanism. This mode selectively releases small soluble catecholamines but retains the larger, less mobile, neuropeptide cargo. Limited mixing of granule and plasma membrane is observed under these conditions. This restricted fusion is followed by a rapid granule-specific membrane internalization and endosomal recycling to form new functional catecholamine-containing granules. Higher activity levels that 
mimic acute stress and sympathetic activation lead to a dilation of the fusion pore and release both the catecholamine and neuropeptide cargos. Endocytosis under this condition is not specific for granule membrane but internalizes general surface membrane. Endosomal processing after stress activation is more complex and takes a longer time to return granules to the releasable population. These differences indicate that differential transmitter release from adrenal chromaffin cells during breed-and-feed versus fight-or-flight metabolic states may be achieved through a size-exclusion mechanism.

\section{Materials and Methods}

Chromaffin cells isolated from the adrenal medullae of adult C57BL/6 mice (4-8 weeks of age) were used in this study. All anesthesia and euthanasia protocols were reviewed and approved by the Institutional Animal Care and Use Committee of Case Western Reserve University, an accredited oversight body (federal animal welfare assurance \#A3145-01). Animals were deeply anesthetized by halothane inhalation and killed by decapitation. All chemicals and reagents were obtained from Sigma (St. Louis, MO) unless otherwise noted in the text.

Cell preparation. Adrenal glands were removed immediately after the animals were killed and were placed in an ice-cold dissociation solution that contained (in mM) $80 \mathrm{Na}$ glutamate, $55 \mathrm{NaCl}, 6 \mathrm{KCl}, 1 \mathrm{MgCl}_{2}, 10$ HEPES, and 10 glucose, $\mathrm{pH} 7.0$, and osmolarity was adjusted to 280 mOsm. Glands were trimmed of fat, and the adrenal cortex was dissected from the medullae. The medullae were then incubated in digest solution for $10 \mathrm{~min}$ at $37^{\circ} \mathrm{C}$ (solution $1: 30 \mathrm{U} / \mathrm{ml}$ papain, $1 \mathrm{~mm} \mathrm{DTT}$, and $0.5 \mathrm{mg} / \mathrm{ml}$ BSA added to $1 \mathrm{ml}$ of dissociation solution). The tissues were then triturated with a $2 \mathrm{ml}$ serological pipette and were transferred into a second digest solution for another $10 \mathrm{~min}$ incubation at $37^{\circ} \mathrm{C}$ (solution $2: 3 \mathrm{U} / \mathrm{ml}$ collagenase $\mathrm{F}, 0.5 \mathrm{mg} / \mathrm{ml} \mathrm{BSA}$, and $100 \mu \mathrm{M} \mathrm{CaCl}{ }_{2}$ added to $1 \mathrm{ml}$ of dissociation solution). After the second incubation, cells were transferred into a DMEM growth medium supplemented with ITS-X artificial serum substitute $(1 \times$; Invitrogen, Carlsbad, CA) and penicillin/streptomycin $(20 \mathrm{U} / \mathrm{ml}$ each) and triturated a second time. Cell-containing supernatant was plated onto glass coverslips, and cells were allowed to settle and adhere to the glass for $15 \mathrm{~min}$. After cell adhesion, $3 \mathrm{ml}$ of DMEM (supplemented as above) was added to the tissue culture well. The cells were incubated at $35^{\circ} \mathrm{C}$ in $10 \% \mathrm{CO}_{2}$, and the experiments were performed $2-3$ $\mathrm{d}$ after cell preparation.

Electrophysiological recordings. For cell electrophysiology measurements, patch pipettes were pulled from borosilicate glass with an inside tip diameter of $\sim 0.3-0.5 \mu \mathrm{m}$. They were partially coated with molten dental wax and lightly polished by a microforge (Narashige, Tokyo, Japan). All recordings in this study were performed in the perforated patch configuration. The perforated patch-pipette solution contained (in $\mathrm{mM}$ ) 135 Cs-glutamate, 10 HEPES-H, $9.5 \mathrm{NaCl}, 0.5 \mathrm{TEA}-\mathrm{Cl}$, and 0.53 amphotericin B, pH 7.4 (osmolarity $300 \mathrm{mOsm}$ ). Amphotericin B was prepared as a $100 \times$ stock solution in DMSO (tissue culture tested; Sigma) daily and diluted into the standard internal pipette solution.

During the experimental recordings, cells were constantly superfused at a rate of $\sim 1 \mathrm{ml} / \mathrm{min}$ with a Ringer's solution of the following composition (in mM): $150 \mathrm{NaCl}, 10$ HEPES-H, 10 glucose, $2.5 \mathrm{CaCl}_{2}, 2.8 \mathrm{KCl}$, and $2 \mathrm{MgCl}_{2}$. The osmolarity was adjusted to $320 \mathrm{mOsm}$ with mannitol, and the $\mathrm{pH}$ was adjusted to 7.2. Patched cells were allowed to perforate to $<30 \mathrm{M} \Omega$ series resistance before recording. The junction potential between the solution set was measured to be $\sim 13.2 \mathrm{mV}$ but was not corrected. Cells were held at $-80 \mathrm{mV}$ command potential. Cells with leak currents greater than $-30 \mathrm{pA}$ were discarded from analysis. Voltageclamp records were acquired through an EPC-9 (HEKA Elektronik, Lambrecht, Germany) amplifier under control of Pulse software (version 8.40; HEKA Elektronik). Cell capacitance was estimated using the software Sine plus DC lock-in module with a sine wave amplitude of $25 \mathrm{mV}$ and at $321 \mathrm{~Hz}$.

Patched cells that exhibited sufficient access conductance and low leak were stimulated with trains of simulated action potentials at either 0.5 or $15 \mathrm{~Hz}$. To compare data across frequencies, stimulation protocols were balanced to evoke the fusion and cycling of a similar number of granules under each frequency. To balance the total number of events, we measured the quantal content under both 0.5 and $15 \mathrm{~Hz}$ as described previously (Chan and Smith, 2003). We found that, in this preparation, $15 \mathrm{~Hz}$ stimulation resulted in an average quantal content of $0.62 \pm 0.11 \mathrm{fF}(n=$ 24 recordings), whereas $0.5 \mathrm{~Hz}$ resulted in a larger mean quantal content of $9.43 \pm 0.85 \mathrm{fF}$ ( $n=27$ recordings). This difference is attributable to granule depletion at the higher activity level that limits granule supply (data not shown). Thus, to balance secretory activity, we stimulated cells with $10 \mathrm{~min}$ trains at $0.5 \mathrm{~Hz}$ and $5 \mathrm{~min}$ trains at $15 \mathrm{~Hz}$ stimulation.

Electrochemical recordings. Commercially available carbon fiber electrodes (ALA Scientific Instruments, Longneck, NY) of $5 \mu \mathrm{m}$ tip diameter were used for amperometric catecholamine detection. Carbon fibers were cut fresh before each recording. A $+650 \mathrm{mV}$ potential was placed on the carbon fiber once it was in the bath, and the background current was allowed to relax to a steady value. If the resting current was larger than 10 pA or was unstable, the fiber was recut or replaced. Amperometric currents were recorded through a dedicated amplifier (VA-10X with $1 \mathrm{G} \Omega$ head stage; ALA Scientific Instruments). The head stages for the VA-10X and EPC-9 amplifiers shared a common Ag-AgCl bath ground. To minimize cross talk between them, a $10 \Omega$ resistor was placed into the ground wire of the VA-10X to separate the ground planes. The tip of the electrode was placed as close to the cell surface as possible during the recording without physically distorting the cell. Oxidative amperometric currents, indicating catecholamine release, were passed through an analog $1 \mathrm{kHz}$ Bessel filter and sampled at $20 \mathrm{kHz}$ through an ITC-1600 (Instrutech, Port Washington, NY) with an acquisition macro written in IGOR Pro (WaveMetrics, Lake Oswego, OR). To ensure synchronization with capacitance measurements, the same signal was also acquired simultaneously in the Pulse software as a second channel. Amperometric records were analyzed with a modified peak detection routine based on the Spike macro (Gomez et al., 2002). We modified the original macro to include analysis of "spike feet." Feet were identified in a recording as a prespike current that lead to an eventual rapidly rising event.

Fluorescence microscopy. Fluorescent images were acquired on an Olympus (Tokyo, Japan) IX70 inverted microscope with a $100 \times$ oilimmersion objective (numerical aperture, 1.3). This objective combined with immersion oil at refractive index of 1.51 predicts a depth-of-field of $115 \mathrm{~nm}$. Cells were excited with a TILL Polychrometer IV (TILL Photonics, Pleasanton, CA) under the control of SlideBook image acquisition software (SlideBook 4.0; Intelligent Imaging Corporation, Denver, CO). Images were captured with a cooled CCD camera (QImaging Corporation, Burnaby, British Columbia, Canada) and stored at 12-bit resolution. Image and data analysis were performed using custom-written macros in IGOR Pro software (WaveMetrics). Fluorescence data in Figure 5 were collected with a photomultiplier tube coupled to a variable aperture acquisition window (ViewFinder; TILL Photonics). The wavelength was controlled by Pulse software (HEKA Elektronik). The cells were then stimulated at either 0.5 or $15 \mathrm{~Hz}$ or were not stimulated. Images were exported to IGOR Pro software (WaveMetrics), where they were analyzed using a line profile histogram developed in-house based on an existing IGOR function.

Chromogranin $A / B$ staining. Ten minutes after stimulation, cells were bath perfused with a fixation Ringer's containing $4 \%$ paraformaldehyde (Electron Microscopy Sciences, Hatfield, PA) and were allowed to fix for $20 \mathrm{~min}$. Cells were then permeabilized with $0.01 \%$ Triton X-100 (Sigma) and incubated with a primary rabbit pan-chromogranin A/B (CgA/B) antibody (11422; MP Biomedicals, Irvine, CA). The cells were then washed and labeled with a rhodamine-tagged goat anti-rabbit IgG secondary antibody to visualize CgA/B (AP187R; MP Biomedicals).

Concanvalin A staining. Concanavalin A (ConA) is a jack bean lectin that irreversibly binds to $\alpha$-mannopyranosyl and $\alpha$-glucopyranosyl residues. In its native unsuccinylated form, ConA forms high molecularweight tetramers that act to cap cells by cross-linking glycosylated receptors, which results in membrane internalization. When ConA is succinylated, it is irreversibly converted to a dimer that binds $\alpha$-mannopyranosyl and $\alpha$-glucopyranosyl residues in the same manner but does not form capping tetramers and does not induce membrane internalization. All ConA staining protocols in this study were performed using succinylated ConA. Cells were superfused with regular Ringer's for 
5 min then superfused with Ringer's containing $10 \mu \mathrm{g} / \mathrm{ml}$ Oregon Green succinylated ConA. Perfusion continued for $\sim 5 \mathrm{~min}$ to allow ConA to bind all available sites (visualized as a stable cell fluorescence). Cells were washed in normal dye-free Ringer's before recording.

Maleimide staining. To control for any residual capping activity from succinylated ConA, we repeated membrane staining protocols in Figure 4 with another irreversible membrane marker. We turned to Alexa 488labeled maleimide, which binds to surface sulfhydryl groups under reduced conditions. Cells were incubated in $1 \mathrm{~mm}$ tris-(2-carboxyethyl) phosphine hydrochloride, a reducing agent, for $10 \mathrm{~min}$ to reduce surface sulfhydryl groups, aiding in more efficient maleimide binding. The cells were then incubated for $10 \mathrm{~min}$ with $10 \mu \mathrm{g} / \mathrm{ml}$ of Alexa 488 maleimide (Molecular Probes, Eugene, OR). Cells were superfused with normal dye-free Ringer's solution for $\sim 5$ min before stimulation protocol.

Dextran/sulforhodamine staining. Cells were superfused with dextran or sulforhodamine (SRB)-containing Ringer's during stimulation. All dextrans were used at $1 \mu \mathrm{M}$, and SRB was used at $10 \mu \mathrm{M}$.

FM1-43/AM1-43 staining. Cells were stained with either $\mathrm{N}$-(3triethylammoniumpropyl)-4-(4-(dibutylamino)styryl) pyridinium dibromide (FM1-43; $800 \mathrm{nM}$; Molecular Probes) or the aminated, fixable analog AM1-43 (10 $\mu \mathrm{M}$; Biotium, Hayward, CA) by bath application in the normal Ringer's solution (see above, Electrophysiological recordings). Cells were perfused with dye-containing Ringer's before, during, and for 1-2 min after stimulation. The dye was left on the cells after stimulation to stain any slowly retrieved membrane populations. Cells were then washed in dye-free Ringer's to remove surface staining.

\section{Results}

Recent studies have shown a heterogeneity in the exocytosis and endocytosis of dense core granules in chromaffin cells. For example, Elhamdani et al. (2001) used amperometric analysis to show that catecholamine quantal size can vary with external calcium or stimulus frequency. Furthermore, the mode of endocytosis has long been known to vary with stimulus intensity (Smith and $\mathrm{Ne}$ her, 1997; Engisch and Nowycky, 1998; Chan and Smith, 2001). We wondered whether a heterogeneity in the exo-endocytosis might be responsible for the differential secretion behavior demanded under sympathetic basal versus stress-activated firing patterns. To test this idea, we investigated several key steps along the exocytic and endocytic cycle predicted to elucidate different modes of exocytosis. Cells were held in the perforated patch configuration and stimulated with trains of 0.5 or $15 \mathrm{~Hz}$ action potential waveforms designed to match native physiological electrical firing patterns exhibited under basal sympathetic tone versus stress-associated sympathetic activation (Brandt et al., 1976; Kidokoro and Ritchie, 1980). To compare secretion across activity levels without undue influences stemming from granule depletion, the duration of 0.5 and $15 \mathrm{~Hz}$ stimulus trains were adjusted such that an equal amount of catecholamine was released at each frequency.

\section{Amperometric spikes are smaller under basal stimulation}

We measured evoked amperometric spike size under basal and stress activation. This technique uses electrochemical oxidation to detect catecholamines as they are released during granule fusion. It does not detect neuropeptide exocytosis. Single traces obtained under 0.5 and $15 \mathrm{~Hz}$ stimulation are provided in Figure $1 \mathrm{~A}$. Total catecholamine release was estimated by integrating the amperometric current over the entire duration of the experiment. As shown (Fig. 1A, $Q_{\text {total }}$, boxed inset), an equivalent amount of catecholamine was released under each condition. Despite this point, single spikes evoked under $15 \mathrm{~Hz}$ stimulation were on average larger than those under $0.5 \mathrm{~Hz}$. We quantified mean spike amplitude (in picoamperes) as well as mean spike charge and provide these values in Figure $1 B\left(Q_{\text {spike }}\right.$, in picocou-
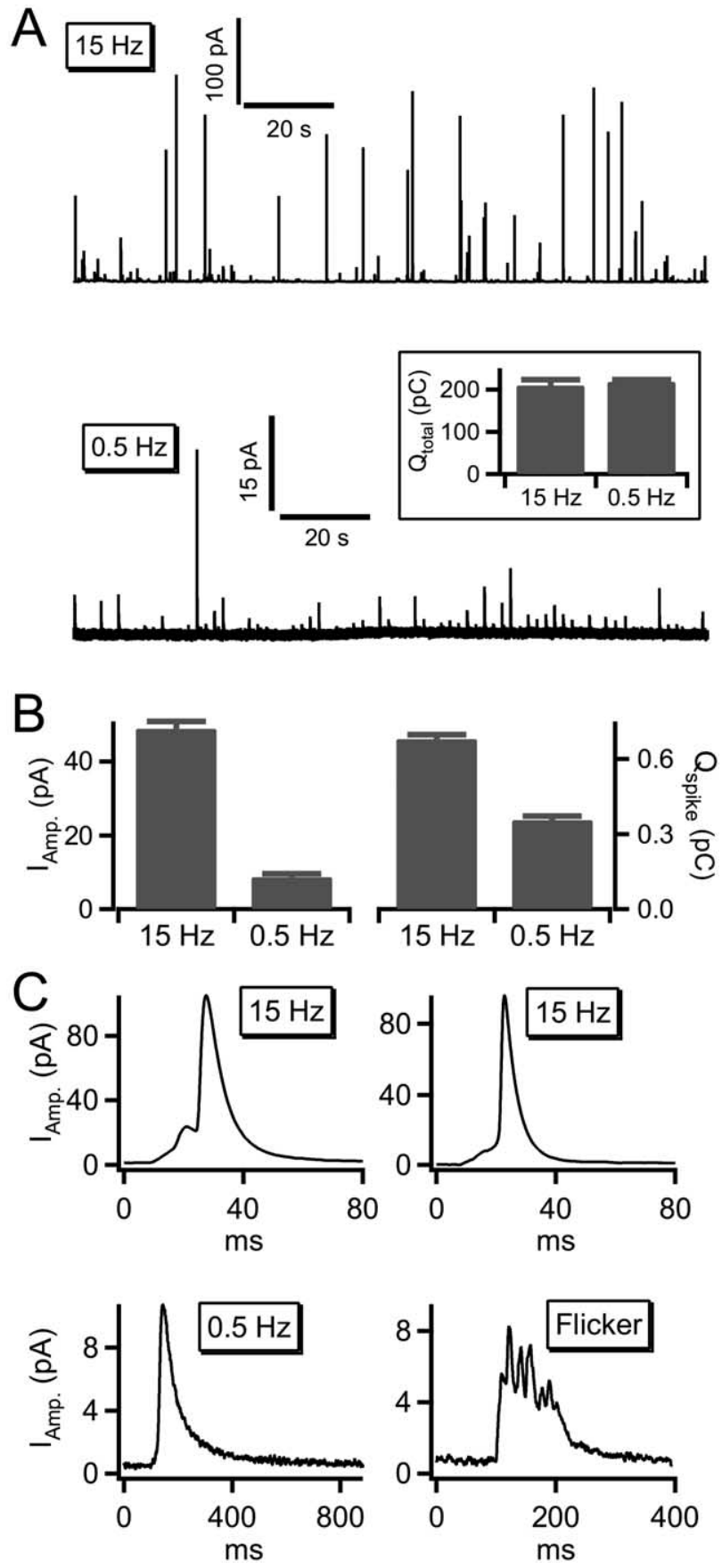

Figure 1. Amperometric spikes vary in size with cell activity. $\boldsymbol{A}$, Carbon fiber amperometry was used to record catecholamine release. Stimulation at $0.5 \mathrm{~Hz}$ elicited spikes at a lower rate than stimulation at $15 \mathrm{~Hz}$. For better visual comparison, both records are presented on the same 150 s time scale and do not represent the entire stimulation epoch. The boxed inset shows total integrated amperometric currents collected from 10 cells stimulated at $0.5 \mathrm{~Hz}$ and 11 cells stimulated at $15 \mathrm{~Hz}$ and confirms the release of approximately the same amount of catecholamine under each condition. $\boldsymbol{B}$, As indicated in the raw records, mean spike amplitude and catecholamine charge integral was smaller in the $0.5 \mathrm{~Hz}$ condition than in the $15 \mathrm{~Hz}$ condition. C, Representative amperometric event from the $15 \mathrm{~Hz}$ conditions and the $0.5 \mathrm{~Hz}$ condition are shown. Stimulation at $0.5 \mathrm{~Hz}$ revealed some conventional spikes as observed under the $15 \mathrm{~Hz}$ condition; however, many smaller, longer-duration events were also observed. In addition, a number of flicker events were observed. Error bars represent SEM.

lombs). These data indicate that mean amperometric quantal size is significantly diminished in basal-firing compared with stressactivated conditions (Elhamdani et al., 2001). Representative single spike events measured under each condition are shown in 
Figure 1C. Amperometric spikes measured under $15 \mathrm{~Hz}$ stimulation were very similar to those described previously in chromaffin cells (Wightman et al., 1991; Chow et al., 1992). They rose rapidly to a peak current of many tens to hundreds of picoamperes and fell back to baseline within a few tens of milliseconds. Often spikes were preceded by "foot" currents that are widely interpreted as the initial opening and stabilization of the fusion pore before eventual dilation (Chow et al., 1992). Amperometric events elicited under $0.5 \mathrm{~Hz}$ stimulation were decidedly smaller and longer in duration than those measured under $15 \mathrm{~Hz}$ trains. Often, events measured at $0.5 \mathrm{~Hz}$ could not be classified as spikes at all, rather they more resembled steps or "flickers" (Fig. 1C, bottom right plot). Additionally, prespike feet were readily identifiable in $\sim 30 \%$ of the events measured under $15 \mathrm{~Hz}$ stimulation but were readily identifiable in only $5 \%$ of the $0.5 \mathrm{~Hz}$ condition. Given that events evoked by $0.5 \mathrm{~Hz}$ stimulation were significantly smaller and were preceded by fewer feet, we wondered whether maybe these events themselves might be analogous to standalone feet (Alvarez de Toledo et al., 1993; Wang et al., 2003) that simply never develop into full spike events, as would be expected from closure of the fusion pore before dilation. Indeed, the mean integrated current measured from foot events under $15 \mathrm{~Hz}$ stimulation was very close to the mean "spike" charge under $0.5 \mathrm{~Hz}$ stimulation $[0.31 \pm 0.01 \mathrm{pC}$ (records from 11 cells) foot charge at $15 \mathrm{~Hz}$ vs $0.36 \pm 0.02 \mathrm{pC}$ (records from 10 cells) spike charge at 0.5 $\mathrm{Hz}]$. Together, these data indicate that the catecholamine release under basal firing conditions results in a smaller quantal size and slower release process than under stress-activated firing.

\section{Endocytosis excludes macromolecules under 0.5 Hz stimulation}

We tested the hypothesis that the smaller and slower amperometric spikes shown in Figure 1 are attributable to a restricted fusion pore between the granule and the plasma membrane, whereas the $15 \mathrm{~Hz}$ stimulation evokes larger events attributable to a dilation of the fusion pore. Variable size fluorescent molecules have been used to probe the diameter of the fusion pore in pancreatic $\beta$ cells (Takahashi et al., 2002). We turned to a similar approach to probe the fusion pore morphology under basal firing versus stress activation in chromaffin cells. A diagram representing this approach is provided in Figure $2 \mathrm{~A}$. We bathed chromaffin cells in extracellular Ringer's solution containing one of several molecular-weight fluorescent markers. The predicted molecular diameters of the markers ranged from $\sim 1.4 \mathrm{~nm}$ (sulforhodamine B) (Takahashi et al., 2002) to $12 \mathrm{~nm}$ (70 kDa Texas Red-labeled dextran) (Ioan et al., 2000). We then stimulated cells with trains of action potentials at either 0.5 or $15 \mathrm{~Hz}$ and monitored fluorescence uptake by imaging the cells. As shown in Figure $2 \mathrm{~B}$, cells stimulated at $0.5 \mathrm{~Hz}$ readily took up SRB but internalized the dextrans with less efficiency as a function of molecular weight. Under basal firing rates, dextrans of 40 and $70 \mathrm{kDa}$ weight were barely internalized at all. We noted that, under $0.5 \mathrm{~Hz}$ stimulation, dye internalization came to a plateau before the end of the stimulus train; this point will be further addressed below. Cells stimulated with $15 \mathrm{~Hz}$ action potential trains took up most of the fluid phase markers with equal efficiencies, except for the largest $70 \mathrm{kDa}$ dextran, which was internalized to a lesser degree. Total marker internalization was measured at the $10 \mathrm{~min}$ time point for all dyes under both stimulation protocols and is summarized in Figure $2 C$. These data indicate that the pore opening between the extracellular space and the endosomal lumen remains restricted in the basal firing condition, allowing smaller markers into the endosome but excluding larger molecules. Stimulation with stress-activated firing patterns results in equal endocytic internalization of all but the largest of the fluid phase markers and indicates a larger opening between granule lumen and extracellular space. This result is consistent with amperometric data in Figure 1; both data sets support the hypothesis that basal firing allows catecholamine release through a restricted fusion intermediate, whereas stress activation leads to a full granule collapse.

\section{Endosomes formed under basal firing retain chromogranins}

The protein core inside chromaffin granules is comprised of structural glycoproteins and contains neuroactive protein transmitters (Rahamimoff and Fernandez, 1997), the most abundant of which are CgA/B (O'Connor and Frigon, 1984). Physiological and ultrastructural studies addressing whether these lumenal proteins are released during fusion report divergent results (Viveros et al., 1969; Albillos et al., 1997; Barg et al., 2002; Perrais et al., 2004). We asked whether the chromaffin cells release neuropeptides as a function of stimulation strength. Initially, we considered several approaches for this experiment. Electron microscopy was eliminated in that this would necessitate isolation and processing of the single patched and stimulated cell. Additionally, it would be difficult to identify only the newly formed endosomes in the micrographs, especially because some are hypothesized to retain electron-dense protein core. We also considered HPLC to measure $\mathrm{CgA} / \mathrm{B}$ release; however, this would necessitate collection of adequate concentrated fluid samples from a single cell during voltage clamp. Instead, we turned to immunocytochemistry coupled to a quantitative image cross-correlation analysis to determine the $\mathrm{CgA} / \mathrm{B}$ content of newly formed endosomes. This approach is summarized in Figure $3 A$ and is designed to estimate the probability of neuropeptide release under basal versus stress activation. We bathed and stimulated cells in the styryl dye AM1-43 (Biotium), which is similar to the more common FM143 , except that it is aminated to allow staining patterns to be preserved after fixation and cell detergent permeablization. Thus, stimulation of cells in the presence of AM1-43 labels recently internalized membranes as they undergo exocytosis and endocytosis, and its label pattern is preserved through immunocytochemical analysis. Labeled cells were fixed by direct perfusion with $4 \%$ formalyne into the recording chamber. Cells were then permeabilized and probed with a pan antibody to both $\mathrm{CgA} / \mathrm{B}$ and counterstained with a secondary rhodamine-labeled antibody. Example images from the AM1-43 and CgA/B label are provided in Figure $3 B$.

We then asked whether newly formed endosomes, stained with AM1-43, still contained CgA/B neuropeptides (rhodamine signal). Because single endosomes are predicted to be similar in size to secretory granules, which are below the resolution of the light microscope, we processed images using a statistical tool. We used a Pearson's cross-correlation analysis to calculate the degree of spatial correlation between newly stained endosomes and granule protein cargo. This approach has previously been successfully used to measure the distribution of subcellular organelles (Zanella et al., 2002). The Pearson's algorithm reports a score between 1 and -1 , with 1 being perfect correlation between the distribution of green and red signals. A score of -1 represents inverse distribution, 0 represents uniform distribution, and 0.4 represents random distribution. A summary of Pearson's scores is reported in Figure $3 C$. A score of $>0.6$ represents statistically highly correlated signals (Fig. $3 C$, dashed line). The mean Pearson's scores for $0.5 \mathrm{~Hz}$ stimulation reached a highly significant value of $0.72 \pm 0.01(n=9)$, whereas the mean Pearson's score for $15 \mathrm{~Hz}$ failed to reach significance at $0.34 \pm 0.01(n=8)$. These 

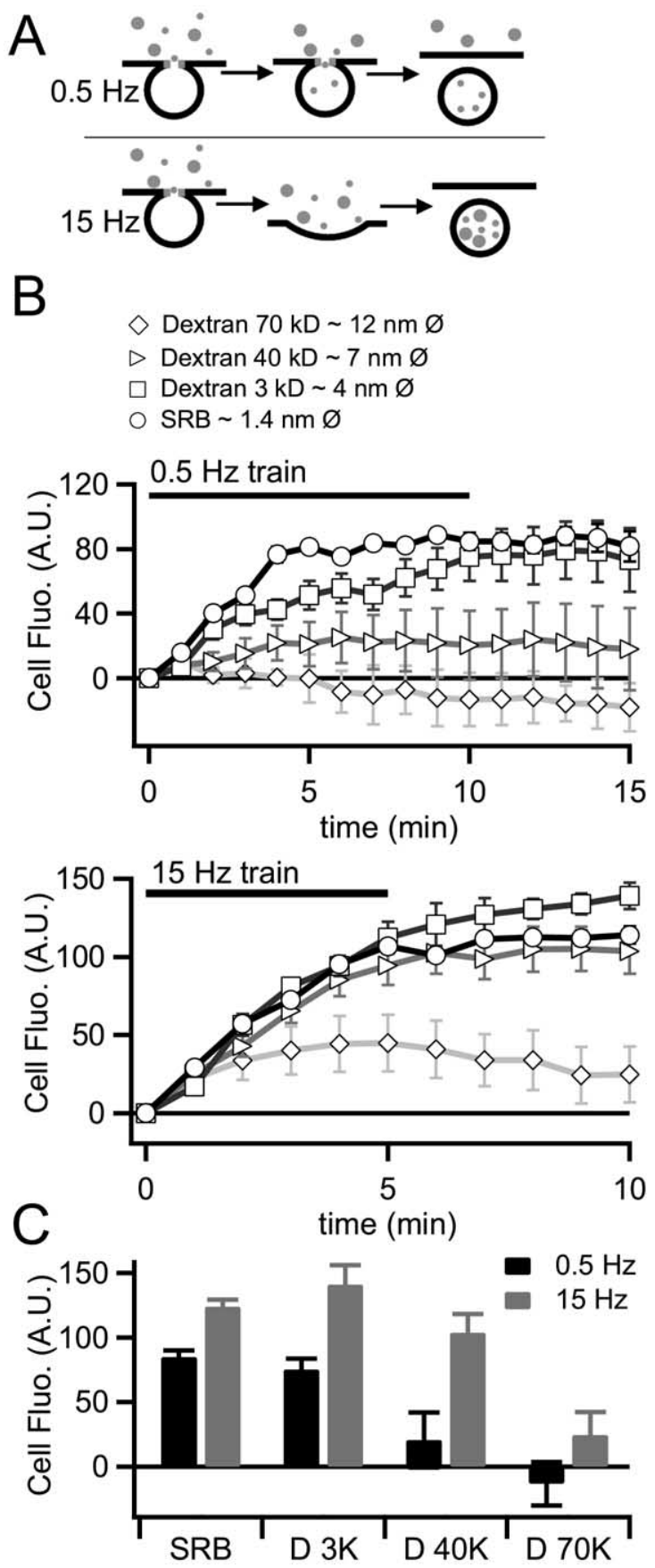

Figure 2. Endosomes exclude marker internalization in an activity and size-dependent manner. $A$, A diagram summarizing the experimental protocol is provided. Cells were stimulated with 0.5 and $15 \mathrm{~Hz}$ action potential waveforms. Fluid phase fluorescent markers of varying diameter were included in the bath solution. $\boldsymbol{B}$, Cells were imaged during the stimulus trains and for 5 min after stimulation. To measure the kinetics of dye uptake, internalized fluorescence (Internal fluo.) was measured off-line on a per-frame basis for each fluorophore and each stimulus condition. $\boldsymbol{B}$, The data from this protocol are plotted for each condition $(0.5 \mathrm{~Hz}$ in the top plot and $15 \mathrm{~Hz}$ in the bottom plot). C, Total internalized fluorescence was quantified at for the entire stimulus period and is plotted for each condition. These data indicate that the pore between the granule lumen and extracellular space remains smaller under $0.5 \mathrm{~Hz}$ than under 15 Hz stimulation. A.U., Arbitrary units. Error bars represent SEM.

data indicate that endosomes formed under $0.5 \mathrm{~Hz}$ stimulation are statistically highly correlated to the neuropeptides $\mathrm{CgA} / \mathrm{B}$. Endosomes generated by $15 \mathrm{~Hz}$ stimulation do not correlate to $\mathrm{CgA} / \mathrm{B}$, presumably because of its exocytosis.
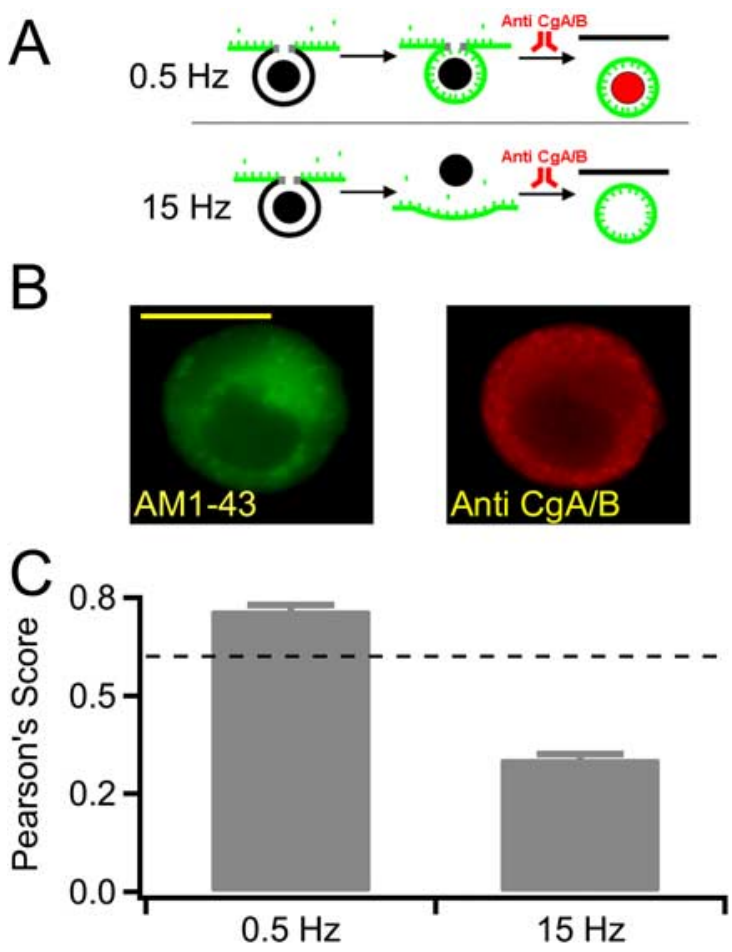

Figure 3. Endosomes retain neuropeptides under $0.5 \mathrm{~Hz}$ stimulation. $\boldsymbol{A}$, A diagram summarizing the experimental protocol is provided. Cells were bathed in $10 \mu \mathrm{m} \mathrm{AM1-43} \mathrm{(green} \mathrm{mark-}$ ers) and stimulated at either 0.5 or $15 \mathrm{~Hz}$. Internalized fluorescence represents recently retrieved endosomal membrane. Cells were fixed $10 \mathrm{~min}$ after stimulation and permeabilized. Chromogranins A and B were detected with a pan antibody and visualized with a rhodamineconjugated secondary antibody. The cells were then washed and labeled with a rhodaminetagged goat anti-rabbit lgG secondary antibody to visualize $\mathrm{CgA} / \mathrm{B}$. B, Sample images of positive control cells are provided. The calculated depth of field of the optical system used for this analysis is $\sim 115 \mathrm{~nm}$; thus, optical sectioning in the $z$-axis is less than the diameter of a single secretory granule. Scale bar, $10 \mu \mathrm{m}$. C, A Pearson's cross-correlation analysis was performed on data collected from 0.5 and $15 \mathrm{~Hz}$ stimulated cells. A score $>0.6$ (dashed line) represents a high degree of cross-correlation. Thus, endosomes generated under $0.5 \mathrm{~Hz}$ stimulation retain their protein core, whereas those generated under $15 \mathrm{~Hz}$ are emptied. Error bars represent SEM.

\section{Basal firing elicits direct endocytosis of the} granule membrane

Pinching off of $\Omega$-form granules after catecholamine release, but before release of neuropeptide matrix (Albillos et al., 1997), would predict that the granule and surface membrane would remain segregated through the exo-endocytic cycle (Ryan, 2003). This may not be the case under stress stimulation if granules collapse entirely into the cell surface, allowing release of the protein matrix. We stained cell membrane with two different irreversible markers, stimulated cells, and followed the fate of the stained membrane. This approach has been used successfully in tracking membrane mixing between secretory granule and plasma membrane in sea urchin eggs (Smith et al., 2000). A cartoon representing the staining protocol is presented in Figure $4 \mathrm{~A}$. We first covalently bound cell-surface sugar groups with Oregon Green-labeled succinylated concanavalin A (O.G. ConA). The succinylated form of ConA does not induce capping of cellsurface glycoprotein receptors and does not induce membrane internalization as does unsuccinylated ConA; thus, the internalization of O.G. ConA would represent specific exocytosiscoupled membrane retrieval. After staining, we washed the cells in ConA-free Ringer's, stimulated cells at 0.5 or $15 \mathrm{~Hz}$, and imaged the redistribution of the fluorescence signal (Fig. 4B). We repeated this protocol with Alexa 488-labeled maleimide, which 

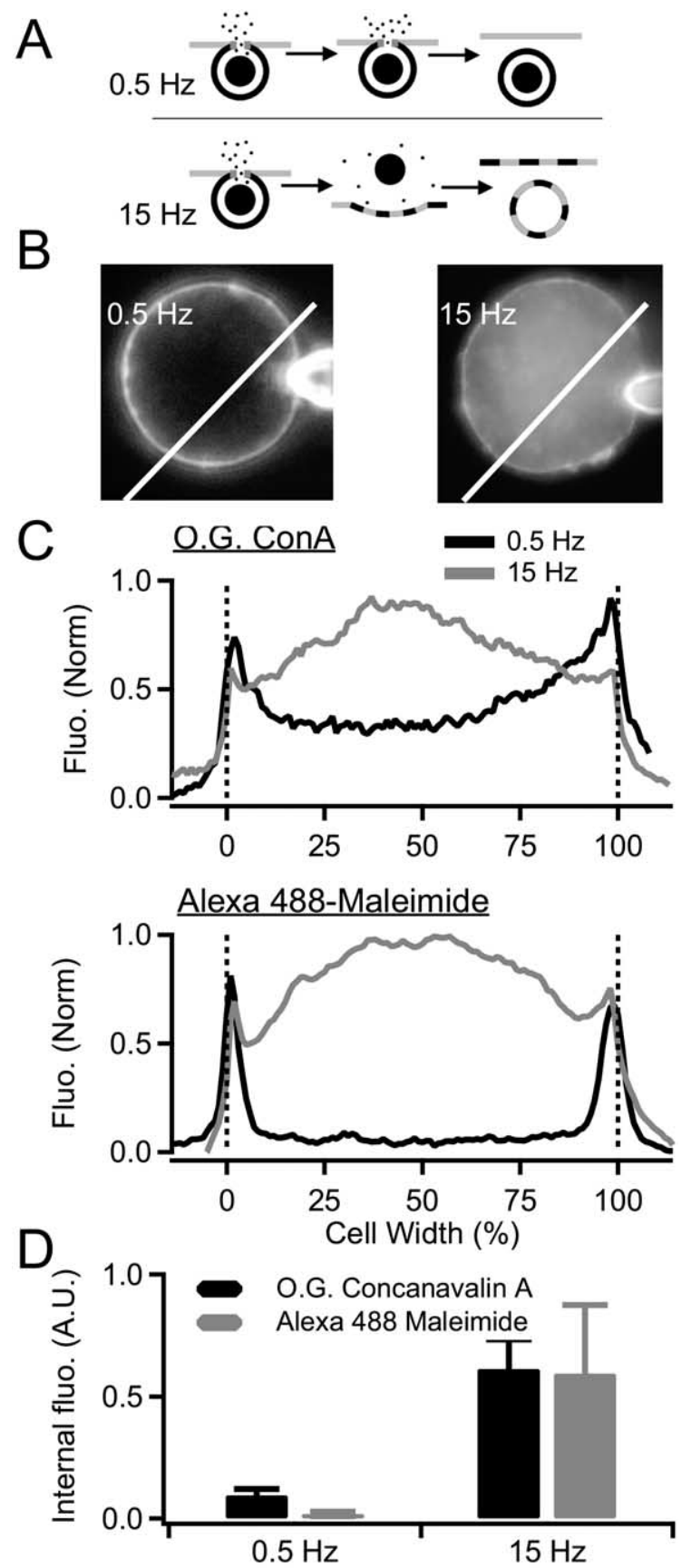

Figure 4. Stimulation at $0.5 \mathrm{~Hz}$ selectively retrieves granule membrane. $\boldsymbol{A}, \mathrm{A}$ diagram summarizing the experimental protocol is provided. Surface-cell membranes were irreversibly labeled with either 0.G. ConA or Alexa 488-taged maleimide. Cells were then washed and stimulated at 0.5 or $15 \mathrm{~Hz}$ to evoke equivalent catecholamine release. Cells were imaged to track the fate of the prelabeled cell-surface membrane. $\boldsymbol{B}$, Example images of cells labeled with 0.G. ConA are provided. Dye internalization was determined by measuring fluorescence (Fluo.) along a line profile drawn through the cell. Scale bar, $5 \mu \mathrm{m}$. C, Example line profiles are provided for cells prelabeled with 0.G. ConA (top plot) or Alexa 488-maleimide (bottom plot) and stimulated at 0.5 and $15 \mathrm{~Hz}$. D, Internalized fluorescence was determined as the mean value in the interior $80 \%$ of the line profile (10-90\% cell width). Average values collected from four cells in each condition are shown. From these data, it is concluded that $0.5 \mathrm{~Hz}$ stimulation results in specific retrieval of granule membrane, whereas $15 \mathrm{~Hz}$ stimulation evokes retrieval of mixed surface and granule membrane. Error bars represent SEM.

covalently labels surface sulfhydryl groups under reduced conditions. We took this step as a control to guard against the influence of any residual capping activity under O.G. ConA staining. Maleimide does not exhibit capping activity under any conditions.
Representative fluorescence profiles for O.G. ConA and Alexa 488-maleimide staining are provided in Figure 4C. The internalized fluorescence measured from all cells under each condition was determined as the average brightness in the interior $80 \%$ of the cell diameter (10-90\% cell diameter to exclude surface staining), values are plotted in Figure $4 D$. Despite equivalent catecholamine release under 0.5 and $15 \mathrm{~Hz}$ stimulation, these data indicate that $\sim 6$ times more plasma membrane is internalized under stress activation than under basal firing conditions. From these data, we conclude that plasma membrane present at the surface of the cell before $0.5 \mathrm{~Hz}$ stimulation remained at the surface after stimulation. Thus, internalized membrane was the same as that added during granule fusion. In contrast, stimulation at $15 \mathrm{~Hz}$ gave a very different result. Much of the dye-labeled plasma membrane was internalized during endocytic membrane uptake, indicating mixing of granule and plasma membrane during exocytosis. Thus, to this point basal stimulation compared with stress activation results in smaller and slowed amperometric spikes, size-dependent internalization of fluid phase markers, retention of protein core markers within endosomes and segregation of granule cell-surface membrane.

\section{Endosomes generated under basal firing undergo rapid recycling}

Classic studies from the Winkler (Lingg et al., 1983; Patzak and Winkler, 1986) and Kirshner (Phillips et al., 1983) groups trace granule membrane endocytosis and trafficking to the trans-Golgi network. Membrane components reappear in newly formed and releasable secretory granules in $\sim 6 \mathrm{~h}$. However, a few studies point to an additional more rapid recycling route that takes just minutes to complete (von Grafenstein and Knight, 1992; Elhamdani et al., 2001). We tested the possibility that relatively intact granules retrieved under $0.5 \mathrm{~Hz}$ stimulation might also undergo a rapid recycling mechanism. We labeled granule membranes during the exo-endocytic cycle and tested for rereleasability within a short time window. We bathed cells in 800 nM FM1-43 and stimulated at $0.5 \mathrm{~Hz}$. As expected, fluorescence of cells increased as unstained granule membrane became exposed to the extracellular dye-containing Ringer's (Smith and Betz, 1996) (Fig. 5Ai). After the first stimulus train, we washed the cells with dye-free Ringer's and allowed them to rest for $\sim 4$ min. Persistent fluorescence represents FM1-43-stained endosomes and marks membrane that recently underwent exocytosis and endocytosis. The cells were then restimulated with the expectation that if the dyelabeled endosomes rapidly reentered the releasable granule population, their re-exocytosis should result in the loss of the recently internalized dye into the dye-free Ringer's. This was found to be the case; we measured an activity-dependent decrease in fluorescence signal during the second stimulus train. A representative data set is supplied in Figure $5 A$. We confirmed that these rapidly recycling granules were functional by measuring catecholamine release under the same conditions (Fig. 5Aii). However, when we conducted the same staining and destaining protocol by dyeloading under $15 \mathrm{~Hz}$ stimulation, we were not able to evoke rerelease of internalized fluorescence with a second stimulus train (proportional dye rerelease during the second stimulus trains was $0.73 \pm 0.10$ for $0.5 \mathrm{~Hz}$ vs $0.07 \pm 0.12$ at $15 \mathrm{~Hz} ; n=6$ and 5 , respectively) (Fig. $5 B$ ). This result indicates that endosomes formed under basal firing differ from those formed under stress activation; they are competent to undergo rapid recycling.

In parallel imaging studies, we tracked the spatial location of the rapidly recycling endosomes formed under $0.5 \mathrm{~Hz}$ by measuring the location and distribution of FM1-43 fluorescence in 

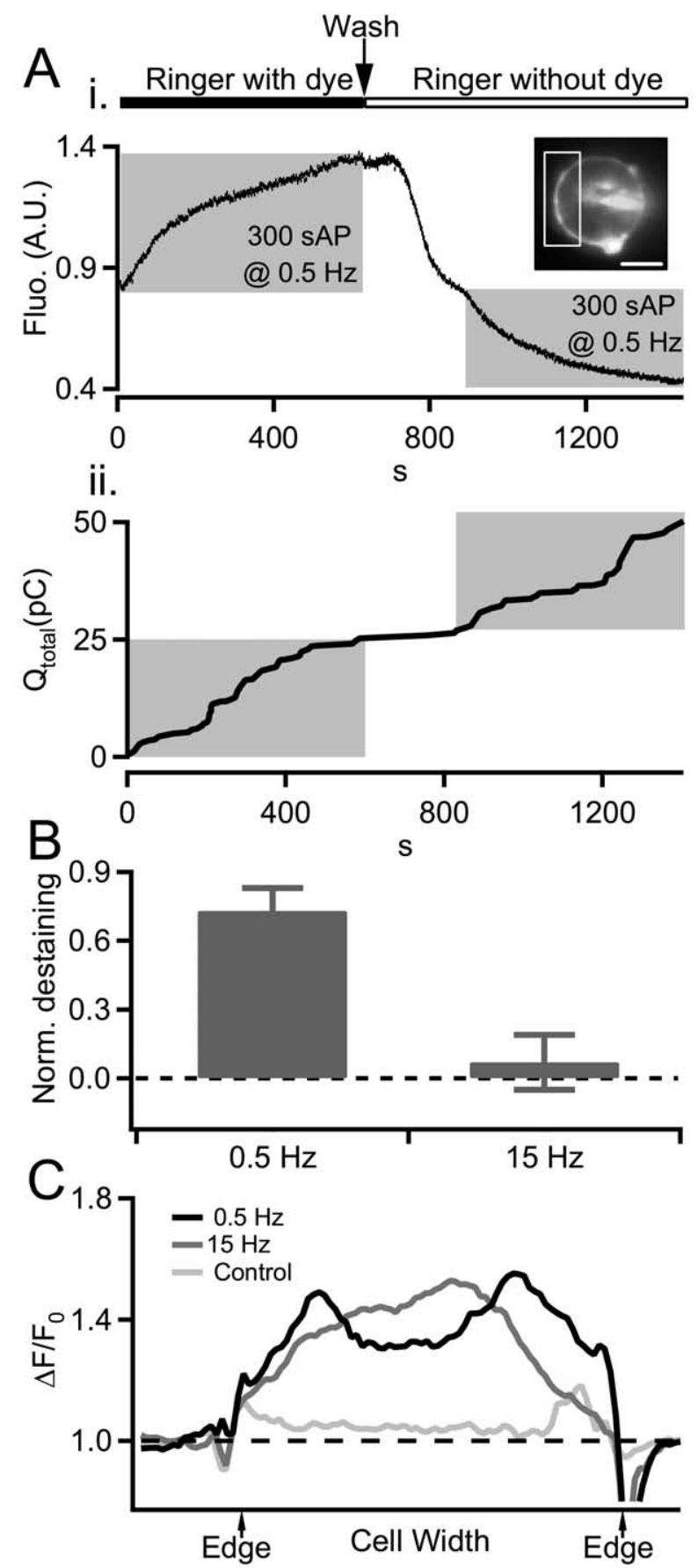

Figure 5. Endosomes generated under $0.5 \mathrm{~Hz}$ stimulation undergo rapid recycling. Ai, Local endosomal recycling was measured under $0.5 \mathrm{~Hz}$ stimulation by combined electrophysiological and fluorometry techniques. A chromaffin cell was bathed in a Ringer's containing $800 \mathrm{~nm}$ FM1-43 and stimulated at $0.5 \mathrm{~Hz}$ to label newly formed endosomes. The cell was then washed in dye-free Ringer's and allowed to rest for $250 \mathrm{~s}$ and then restimulated with a second train of action potential waveforms again at $0.5 \mathrm{~Hz}$. FM1-43 staining and destaining was measured by a photomultiplier tube through a limited aperture opening set to collect light emitted from the cell surface and a representative portion of cytosol but not the brightly labeled patch-pipette contact point (box in inset). We attenuated the light intensity by passing it through a $5 \%$ transmission neutral-density filter to guard against photobleach and damage during the prolonged exposure used in this protocol. The activity-dependent decrease in fluorescence (Fluo.) during the second stimulus train indicates reuse of newly internalized endosomal membrane. Aii, Amperometry current measured during the same protocol used to generate $A$ show that the release of newly internalized FM1-43 is accompanied by catecholamine release. $\boldsymbol{B}$, The staining/ destaining protocol presented in $A$ was repeated on cells stimulated at $0.5 \mathrm{~Hz}(n=6)$ and $15 \mathrm{~Hz}$ $(n=5)$. Dye rerelease was determined as fluorescence decrease during the second train normalized (Norm.) against dye uptake in the first train $(0=$ no dye rerelease; $1=$ complete dye the cytosol compared with $15 \mathrm{~Hz}$ stimulation (Fig. 5C). We found that the labeled endosomes formed under $0.5 \mathrm{~Hz}$ remained near the edge of the cell. Those generated by $15 \mathrm{~Hz}$ stimulation localized to the interior of the cell, as expected for a recycling path that passes through the trans-Golgi network for replacement of protein cargos (Phillips et al., 1983). Together, our results indicate that basal stimulation leads to altered catecholamine release through a restricted fusion pore, but does not allow core protein markers to be released. The fused granules are retrieved relatively intact, undergo a rapid and local recycling near the periphery of the cell, and are rereleasable within a few minutes as functional, catecholamine-containing granules.

\section{Discussion}

We investigated catecholamine and neuropeptide release from adrenal chromaffin cells. We evoked exocytosis under physiological stimulation patterns designed to match sympathetic input under basal breed and feed as well as stress-activated fight or flight stimulation. Our data support an activity-dependent shift in the mode of exocytosis, endocytosis, and granule trafficking between these two states that results in activity-dependent differential transmitter release.

Chromaffin granule exocytosis and subsequent recycling of specialized granule membrane components has been well studied. Results obtained over many years, using bath stimulation with potent secretory agents, showed that granule fusion was followed by collapse into the plasma membrane and neuropeptide release (Viveros et al., 1969; Kobayashi and Serizawa, 1979; Wilson et al., 1981). Under these conditions, release of granule contents was complete (Viveros et al., 1971). Clathrin-mediated endocytosis (Geisow et al., 1985) then retrieved membrane from the cell surface. Internalized endosomes were transported back to the trans-Golgi Network for sorting and repackaging with peptide cargos. This endosomal translocation occurred within $\sim 30$ $\mathrm{min}$ and was followed by a $6 \mathrm{~h}$ delay before the membrane components reappeared in newly synthesized releasable granules (Lingg et al., 1983; Patzak and Winkler, 1986).

However, more recent studies using stimulation paradigms that more closely match electrical physiological activation point to alternate modes of endocytosis. It has recently been shown in neuronal preparations that decreasing cell stimulation may shift secretory vesicle exocytosis from a complete fusion to a more rapid and transient event that leads to a rapid and local membrane reuptake (Koenig and Ikeda, 1996; Richards et al., 2000; Aravanis et al., 2003; Gandhi and Stevens, 2003). Work from our laboratory as well as others drew similar conclusions in chromaffin cells. Evoked endocytosis shifts in kinetic, pharmacologic, and mechanistic character with cell activity. These studies demonstrate that modest stimulation conditions evoke catecholamine release, followed by membrane retrieval through a rapid and clathrin-independent mechanism (Chan and Smith, 2001; Ar-

$\leftarrow$

rerelease). Data pooled from all cells are presented in the category plot and consistent with a local and rapid endosomal path under $0.5 \mathrm{~Hz}$ stimulation but not under $15 \mathrm{~Hz}$ stimulation. C, Internalized fluorescence traces endosomal trafficking. To determine the destination of endosomes we measured the internalized FM1-43 signal along line profiles drawn through cells after stimulation (as in Fig. 4C. Representative profiles obtained after stimulation by $0.5 \mathrm{~Hz}, 15$ $\mathrm{Hz}$, or unstimulated control cells are plotted. Profiles shown are $\Delta F / F_{0}$, where $F_{0}$ represents prestimulus FM1-43 staining. These data show that endosomes generated under $0.5 \mathrm{~Hz}$ stimulation remain near the periphery of the cell, whereas those generated under $15 \mathrm{~Hz}$ stimulation traffic to the center of the cell. A.U., Arbitrary units; Wash, washout; SAP, simulated action potential. Error bars represent SEM. 


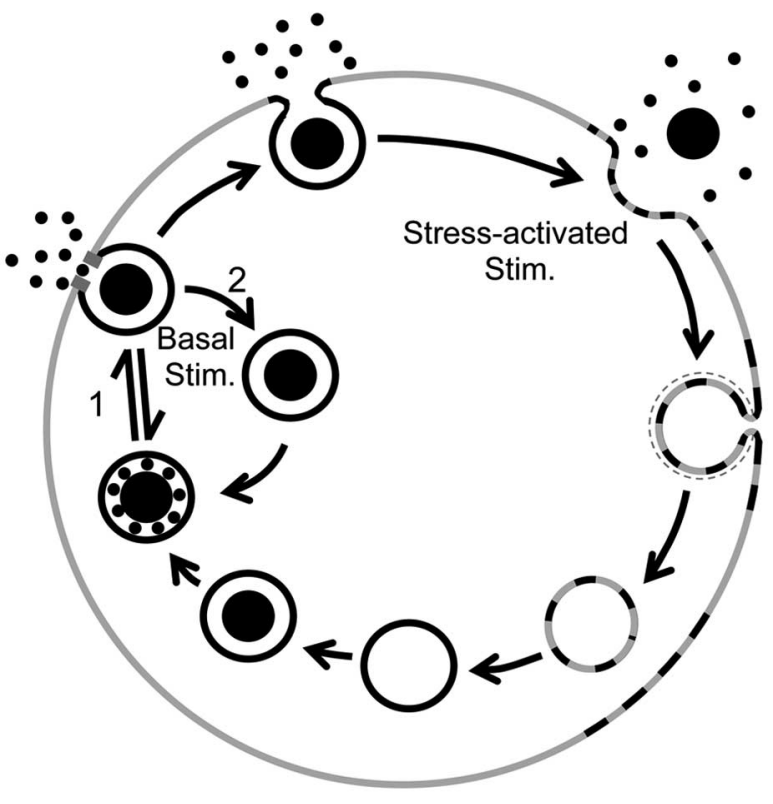

Figure 6. A proposed mechanism for activity-dependent differential transmitter release in adrenal chromaffin cells. Stim., Stimulation.

talejo et al., 2002; Graham et al., 2002). Indeed, if this clathrinindependent endocytosis is of the kiss and run variety (Henkel et al., 2000) with an exocytic pore of $\sim 4 \mathrm{~nm}$ in diameter (Klyachko and Jackson, 2002), it is likely that the granule protein core is retained in the endosome despite catecholamine release (Albillos et al., 1997; Barg et al., 2002). Such a postfusion regulation of transmitter release showed to be physiologically significant in pituitary lactotrophs. Work from the Betz laboratory (Angleson et al., 1999) showed prolactin release to be controlled after granule fusion through a cAMP-dependent retention of the neuropeptide-containing granule protein matrix.

We provide similar evidence for selective activity-dependent transmitter release in this report. A proposed mechanism for this model is provided in Figure 6 and addresses the observation that catecholamine and neuropeptides are differentially released according to sympathetic activity (Takiyyuddin et al., 1990, 1994; Watkinson et al., 1990). Under low activity levels, chromaffin cells contribute to the breed and feed state by releasing catecholamine from secretory granules through a restricted fusion pore (Figs. 1, 2). Neuropeptides are retained in the $\Omega$ figure (Fig. 3) because of a simple size exclusion. Granules are pinched back relatively intact (Fig. 4) to form endosomes that are locally recycled and rapidly return functional granules (Fig. 5). Indeed, this rapid recycling process is not only observed in the direct test provided in Figure 5 but also emerges in a less noticeable but equally compelling feature of the SRB uptake described in Figure 3. We noted that the SRB internalization came to a relatively rapid plateau despite the fact that catecholamine release continues throughout the stimulus train (Figs. 1, 5). This may be attributable to the rerelease of newly internalized SRB from rapidly recycling granules. This same kinetic is also seen in the slowing of FM1-43 uptake in the initial dye-loading segment in Figure 5A, despite continued catecholamine release (Fig. 5). Thus, chromaffin cells exhibit a rapid and robust local recycling of granules under basal stimulation.

A shift in stimulus intensity to the acute stress condition results in an exo-endocytosis mode consistent with that described previously in the literature. In hindsight, this makes sense in that early biochemical studies used relatively long-term chemical stimulation. These conditions likely match high-frequency electrical stimulation in that both result in long-lasting, highly elevated cytosolic calcium levels. This mode of granule fusion evokes a rapid catecholamine release, likely attributable to a dilation of the fusion pore. Fused granules are not kept separate from plasma membrane, but rather they mix before membrane internalization. This full-collapse mode results in the corelease of both catecholamine and neuropeptide and meets the requirements set out by the fight-or-flight sympathetic state.

Here, we provide a mechanism that differentiates between activity-dependent catecholamine and chromogranin release. However, recent evidence exists indicating that regulation of exocytosis among peptides may be further subdivided. Work by the Almers laboratory (Perrais et al., 2004) indicates that the release of NPY and tissue plasminogen activator (TPA) peptide may be separately regulated in chromaffin cells, with NPY rapidly released after granule fusion while TPA remained behind. The data presented in this study detail a mechanism for selective catecholamine release but may extend to explain the observed selective release of NPY over TPA. Indeed, NPY has a molecular weight of $\sim 11 \mathrm{kDa}$, whereas TPA has a molecular weight of $70 \mathrm{kDa}$. As presented in Figure 2, we find a molecular "sieve" that allows passage of sugar molecules of $<40 \mathrm{kDa}$ but excludes molecules of greater mass. If extended to peptides, this may allow the exocytosis of NPY but retain TPA as observed (Perrais et al., 2004). Additionally, it is not clear whether the granule recapture under basal firing conditions represents true kiss-and-run endocytosis (position 1, Fig. 6), characterized by Ryan (2003) as a simple reversal of the fusion pore. It may equally represent a "fusepinch-linger" mechanism (Ryan, 2003), whereby the stabilized $\Omega$ figure is internalized by a regulated endocytic, dynamindependent process (position 2, Fig. 6). Additional biophysical and molecular studies will be required to answer these two outstanding questions.

\section{References}

Albillos A, Dernick G, Horstmann H, Almers W, Alvarez de Toledo G, Lindau M (1997) The exocytotic event in chromaffin cells revealed by patch amperometry. Nature 389:509-512.

Alvarez de Toledo G, Fernández-Chacón R, Fernández JM (1993) Release of secretory products during transient vesicle fusion. Nature 363:554-558.

Angleson JK, Cochilla AJ, Kilic G, Nussinovitch I, Betz WJ (1999) Regulation of dense core release from neuroendocrine cells revealed by imaging single exocytotic events. Nat Neurosci 2:440-446.

Aravanis AM, Pyle JL, Tsien RW (2003) Single synaptic vesicles fusing transiently and successively without loss of identity. Nature 423:643-647.

Artalejo CR, Elhamdani A, Palfrey HC (2002) Sustained stimulation shifts the mechanism of endocytosis from dynamin-1-dependent rapid endocytosis to clathrin- and dynamin-2-mediated slow endocytosis in chromaffin cells. Proc Natl Acad Sci USA 99:6358-6363.

Barg S, Olofsson CS, Schriever-Abeln J, Wendt A, Gebre-Medhin S, Renstrom E, Rorsman P (2002) Delay between fusion pore opening and peptide release from large dense-core vesicles in neuroendocrine cells. Neuron 33:287-299.

Brandt B, Hagiwara S, Kidokoro Y, Miyazaki S (1976) Action potentials in the rat chromaffin cell and effects of acetylcholine. J Physiol (Lond) 263:417-439.

Cavadas C, Silva AP, Cotrim MD, Ribeiro CA, Brunner HR, Grouzmann E (2002) Differential secretion of catecholamine and neuropeptide $\mathrm{Y}$ in response to $\mathrm{KCl}$ from mice chromaffin cells. Ann NY Acad Sci 971:335-337.

Chan SA, Smith C (2001) Physiological stimuli evoke two forms of endocytosis in bovine chromaffin cells. J Physiol (Lond) 537:871-885.

Chan SA, Smith C (2003) Low frequency stimulation of mouse adrenal slices reveals a clathrin-independent, protein kinase C-mediated endocytic mechanism. J Physiol (Lond) 553 3:707-717. 
Chow RH, von Rüden L, Neher E (1992) Delay in vesicle fusion revealed by electrochemical monitoring of single secretory events in adrenal chromaffin cells. Nature 356:60-63.

Elhamdani A, Palfrey HC, Artalejo CR (2001) Quantal size is dependent on stimulation frequency and calcium entry in calf chromaffin cells. Neuron 31:819-830.

Engisch KL, Nowycky MC (1998) Compensatory and excess retrieval: two types of endocytosis following single step depolarizations in bovine adrenal chromaffin cells. J Physiol (Lond) 506:591-608.

Gandhi SP, Stevens CF (2003) Three modes of synaptic vesicular recycling revealed by single-vesicle imaging. Nature 423:607-613.

Geisow MJ, Childs J, Burgoyne RD (1985) Cholinergic stimulation of chromaffin cells induces rapid coating of the plasma membrane. Eur J Cell Biol 38:51-56.

Giampaolo B, Angelica M, Antonio S (2002) Chromogranin 'A' in normal subjects, essential hypertensives and adrenalectomized patients. Clin Endocrinol (Oxf) 57:41-50.

Gomez JF, Brioso MA, Machado JD, Sanchez JL, Borges R (2002) New approaches for analysis of amperometrical recordings. Ann NY Acad Sci 971:647-654

Graham ME, O'Callaghan DW, McMahon HT, Burgoyne RD (2002) Dynamin-dependent and dynamin-independent processes contribute to the regulation of single vesicle release kinetics and quantal size. Proc Natl Acad Sci USA 99:7124-7129.

Henkel AW, Meiri H, Horstmann H, Lindau M, Almers W (2000) Rhythmic opening and closing of vesicles during constitutive exo- and endocytosis in chromaffin cells. EMBO J 19:84-93.

Ioan C, Aberle T, Burchard W (2000) Structure properties of dextran. 2. Dilute solution. Macromolecules 33:5730-5739.

Kidokoro Y, Ritchie A (1979) Effect of tetrodotoxin on adrenaline secretion in the perfused rat adrenal medulla. Nature 278:63-65.

Kidokoro Y, Ritchie AK (1980) Chromaffin cell action potentials and their possible role in adrenaline secretion from rat adrenal medulla. J Physiol (Lond) 307:199-216.

Klyachko VA, Jackson MB (2002) Capacitance steps and fusion pores of small and large-dense-core vesicles in nerve terminals. Nature 418:89-92.

Kobayashi S, Serizawa Y (1979) Stress-induced degranulation accompanied by vesicle formation in the adrenal chromaffin cells of the mouse. Arch Histol Jpn 42:375-388

Koenig JH, Ikeda K (1996) Synaptic vesicles have two distinct recycling pathways. J Cell Biol 135:797-808.

Lingg G, Fischer CR, Schmidt W, Winkler H (1983) Exposure of an antigen of chromaffin granules on cell surface during exocytosis. Nature 301:610-611.

O'Connor DT, Frigon RP (1984) Chromogranin A, the major catecholamine storage vesicle soluble protein. Multiple size forms, subcellular storage, and regional distribution in chromaffin and nervous tissue elucidated by radioimmunoassay. J Biol Chem 259:3237-3247.

Patzak A, Winkler H (1986) Exocytotic exposure and recycling of membrane antigens of chromaffin granules: ultrastructural evaluation after immunolabeling. J Cell Biol 102:510-515

Perrais D, Kleppe I, Taraska J, Almers W (2004) Recapture after exocytosis causes differential retention of protein in granules of bovine chromaffin cells. J Physiol (Lond) 560:413-428.

Phillips JH, Burridge K, Wilson SP, Kirshner N (1983) Visualization of the exocytosis/endocytosis secretory cycle in culture adrenal chromaffin cells. J Cell Biol 97:1906-1917.

Rahamimoff R, Fernandez JM (1997) Pre- and postfusion regulation of transmitter release. Neuron 18:17-27.

Richards DA, Guatimosim C, Betz WJ (2000) Two endocytic recycling routes selectively fill two vesicle pools in frog motor nerve terminals. Neuron 27:551-559.

Ryan TA (2003) Kiss-and-run, fuse-pinch-and-linger, fuse-and-collapse: the life and times of a neurosecretory granule. Proc Natl Acad Sci USA 100:2171-2173

Smith C, Neher E (1997) Multiple forms of endocytosis in bovine adrenal chromaffin cells. J Cell Biol 139:885-894.

Smith CB, Betz WJ (1996) Simultaneous independent measurement of endocytosis and exocytosis. Nature 380:531-534.

Smith RM, Baibakov B, Ikebuchi Y, White BH, Lambert NA, Kaczmarek LK, Vogel SS (2000) Exocytotic insertion of calcium channels constrains compensatory endocytosis to sites of exocytosis. J Cell Biol 148:755-767.

Takahashi N, Kishimoto T, Nemoto T, Kadowaki T, Kasai H (2002) Fusion pore dynamics and insulin granule exocytosis in the pancreatic islet. Science 297:1349-1352

Takiyyuddin MA, Cervenka JH, Sullivan PA, Pandian MR, Parmer RJ, Barbosa JA, O'Connor DT (1990) Is physiologic sympathoadrenal catecholamine release exocytotic in humans? Circulation 81:185-195.

Takiyyuddin MA, Brown MR, Dinh TQ, Cervenka JH, Braun SD, Parmer RJ, Kennedy B, O'Connor DT (1994) Sympatho-adrenal secretion in humans: factors governing catecholamine and storage vesicle peptide corelease. J Auton Pharmacol 14:187-200.

Viveros OH, Arqueros L, Kirshner N (1969) Quantal secretion from adrenal medulla: all-or-none release of storage vesicle content. Science 165:911-913.

Viveros OH, Arqueros L, Kirshner N (1971) Mechanism of secretion from the adrenal medulla. VII. Effect of insulin administration on the buoyant density, dopamine-hydroxylase, and catecholamine content of adrenal storage vesicles. Mol Pharmacol 7:444-454.

von Grafenstein H, Knight DE (1992) Membrane recapture and early triggered secretion from the newly formed endocytotic compartment in bovine chromaffin cells. J Physiol (Lond) 453:15-31.

Wang CT, Lu JC, Bai J, Chang PY, Martin TF, Chapman ER, Jackson MB (2003) Different domains of synaptotagmin control the choice between kiss-and-run and full fusion. Nature 424:943-947.

Watkinson A, O’Sullivan AJ, Burgoyne RD, Dockray GJ (1990) Differential accumulation of catecholamines, proenkephalin- and chromogranin A-derived peptides in the medium after chronic nicotine stimulation of cultured bovine adrenal chromaffin cells. Peptides 11:435-441.

Wightman RM, Jankowski JA, Kennedy RT, Kawagoe KT, Schroeder TJ, Leszczyszyn DJ, Near JA, Diliberto EJ, Viveros OH (1991) Temporally resolved catecholamine spikes correspond to single vesicle release from individual chromaffin cells. Proc Natl Acad Sci USA 88:10754-10758.

Wilson SP, Slepetis R, Chang KJ, Kirshner N, Viveros OH (1981) Differential secretion of opioid peptides and catecholamines from cultured cells of a human pheochromocytoma tumor. Life Sci 29:2257-2264.

Winkler H, Westhead E (1980) The molecular organization of adrenal chromaffin granules. Neuroscience 5:1803-1823.

Zanella B, Calonghi N, Pagnotta E, Masotti L, Guarnieri C (2002) Mitochondrial nitric oxide localization in $\mathrm{H} 9 \mathrm{c} 2$ cells revealed by confocal microscopy. Biochem Biophys Res Commun 290:1010-1014. 